\title{
Using modern experimental equipment to determine process vibration effects on building and the human body
}

\author{
Daniel Papán, Zuzana Papánová, Bibiána Martinovičová \\ University of Žilina \\ Univerzitná 8215/1, 01026 Žilina \\ Slovak Republic
}

Received: May 16, 2021. Revised: December 5, 2021. Accepted: December 21, 2021. Published: January 9, 2022.

\begin{abstract}
The paper presents the original results of an experimental dynamic study of the impact of vibrations generated by a manufacturing process on a building and its occupants. Machinery can cause extraordinary dynamic loads through technical seismicity. For research and education purposes, the article includes a methodology for measuring and evaluating random vibration in the context of assessing the adverse effects of vibration. In particular, this involves the identification of the dominant frequency bands, the amplitude and frequency composition, and the identification of the main source of vibration. For these purposes, the experiments were divided into different measurement stages. Each stage pursued a specific objective. The resulting processed data were evaluated according to the target impact groups. The paper includes an assessment of the vibration impacts on the building and human body, discussion, conclusions, and recommendations.
\end{abstract}

Key words - technical seismicity, experimental methods in mechanics, dynamic response, frequency analysis, octave bands

\section{INTRODUCTION}

$\mathrm{C}_{\mathrm{r}}$ ELLULOSE production on an industrial scale typically requires equipment that generates significant vibrations. This article describes a case study as an example for the measurement and analysis of the dynamic effects of such equipment. Since the vibrations are produced by machines and propagated through the geological environment, this area of study is referred to as technical seismicity. [1,2,3]

This case study investigates the effect of technical seismicity on the building and people in a cellulose plant's administrative section. The load-bearing structure of the plant's administrative section is a compact reinforced concrete structure assumed to be using a continuous slab.

The affected area is approximately $40 \mathrm{~m}^{2}$. Fig. 1 shows views of the building under investigation from the design documentation. [4]

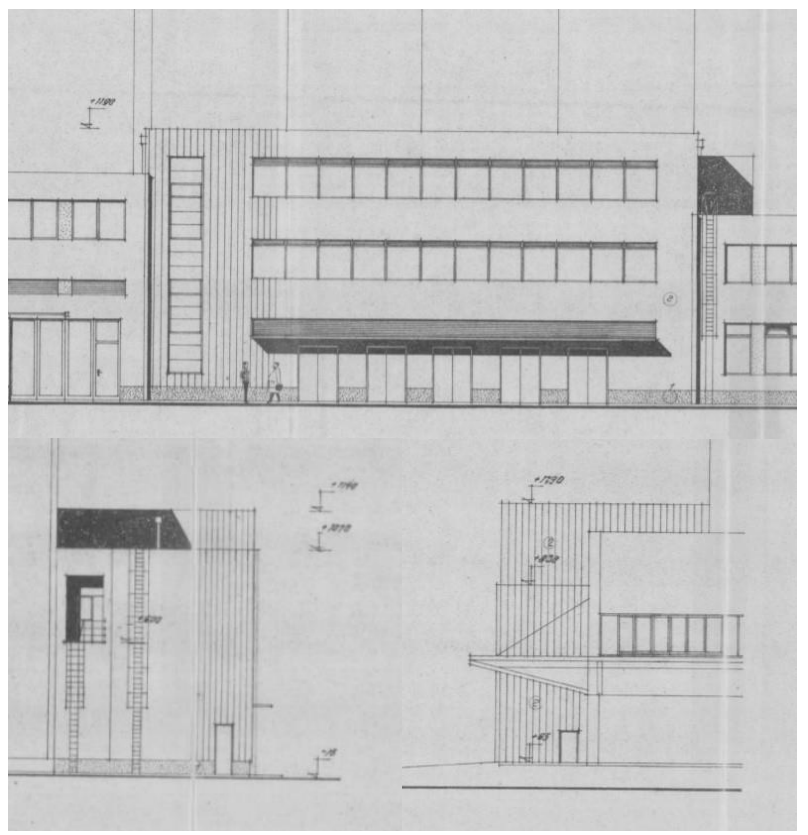

Fig. 1 Design documentation for the building under investigation

The present study considered vibrations from the following sources: Fibreflow FF300 Dissolving Drum, referred to as source 1 (Fig. 2) and two cellulose mills jointly referred to as source 2 (Fig. 3). In normal operation, both machines run simultaneously.

The key parameters of source 1 include:

- drum rotations: $16 \mathrm{rpm}$.

- drum weight at point 5 with full load $=60$ tonnes 
- drum weight at point 4 with full load $=30$ tonnes

Source 2 can be described as a low-frequency rotation mechanism with a random, asynchronous cycle.

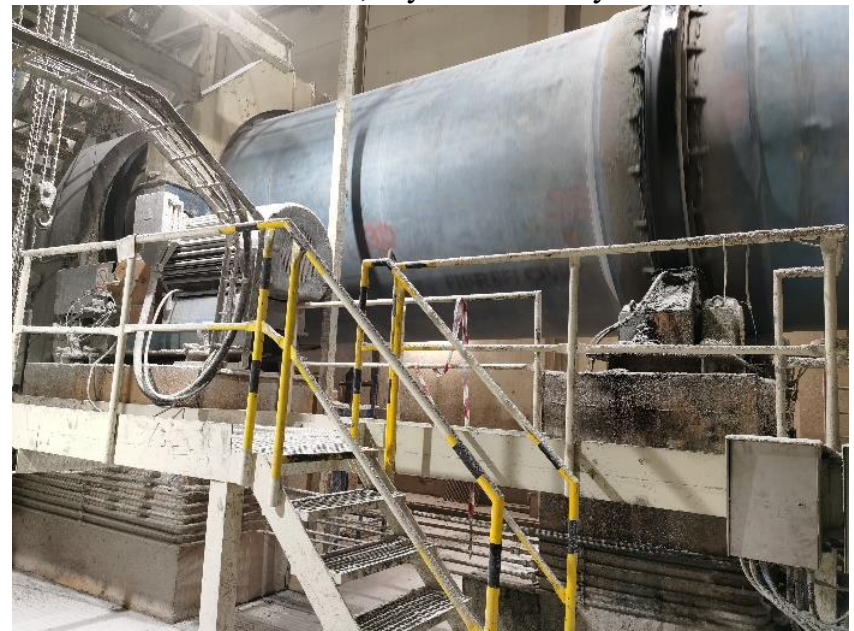

Fig. 2 Fibreflow FF300 Dissolving Drum (source 1)

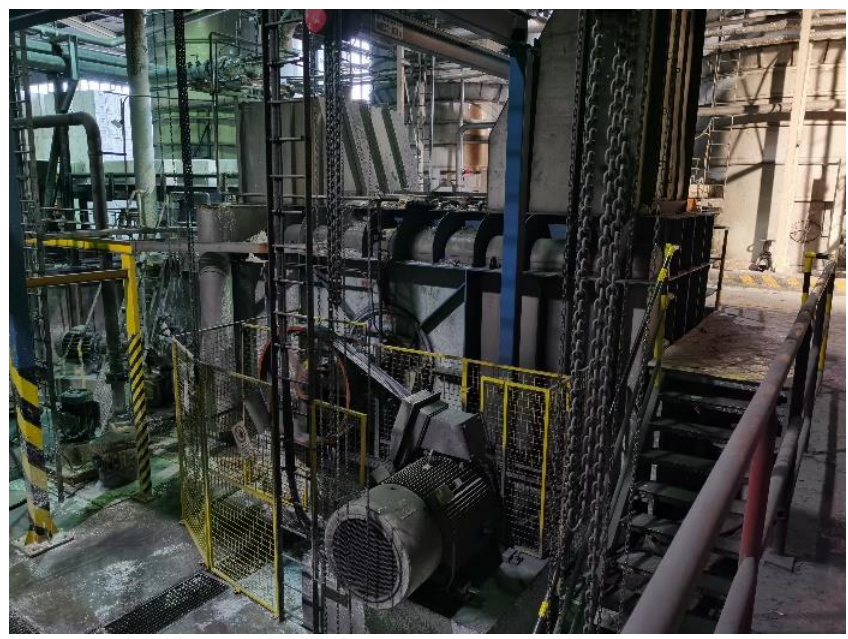

Fig. 3 Cellulose mills (source 2)

The main aim of experimental measurement was to determine vibration levels in the vicinity of the sources. Individual measurements monitored frequencies at various dynamic loads and evaluated the amplitude response in the form of the maximum, minimum and effective values for the velocity and acceleration of vibration. The impact on the human body was determined using a one-third octave band analysis with the corresponding weighting filters. [5]

\section{MEASUREMENT EQUiPMENT USED}

A system of measurement and evaluation is defined to carry out experimental measurements providing objective, dynamic results. In the present case study, the following components and equipment were used (Fig. 4):

- HP Notebook

- LAN cable

- PULSE six-channel analyser

- coaxial cable

- DeltaTron piezoelectric accelerometers of type 4508 B002 with the connector on the upper surface.

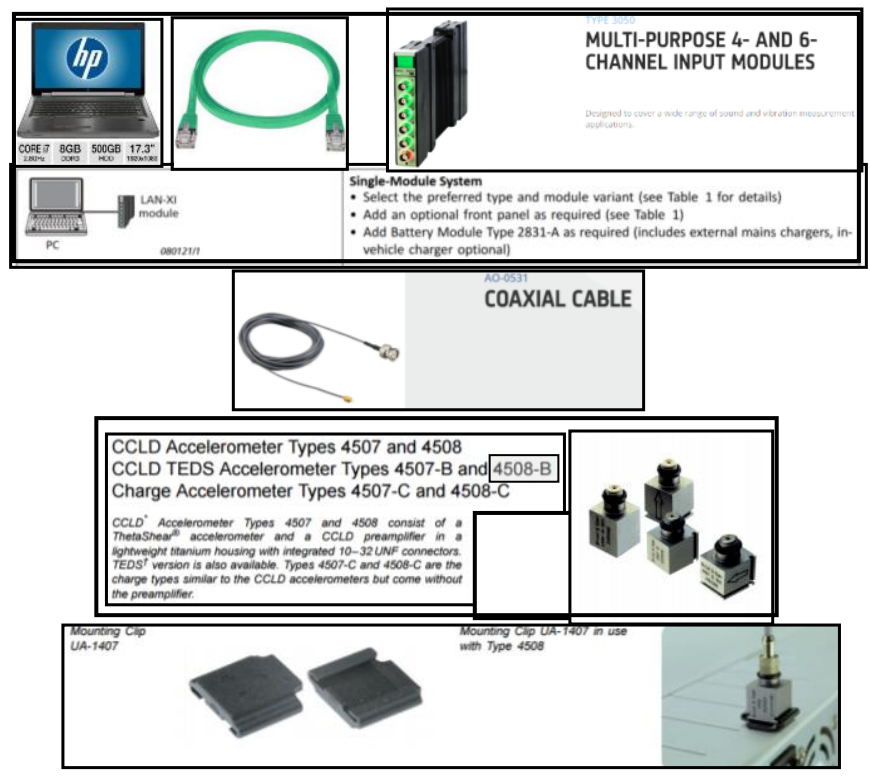

Fig. 4 Measurement instruments

Fig. 5 shows the measurement and analysis equipment listed above and how the components are connected. $[6,7,8]$

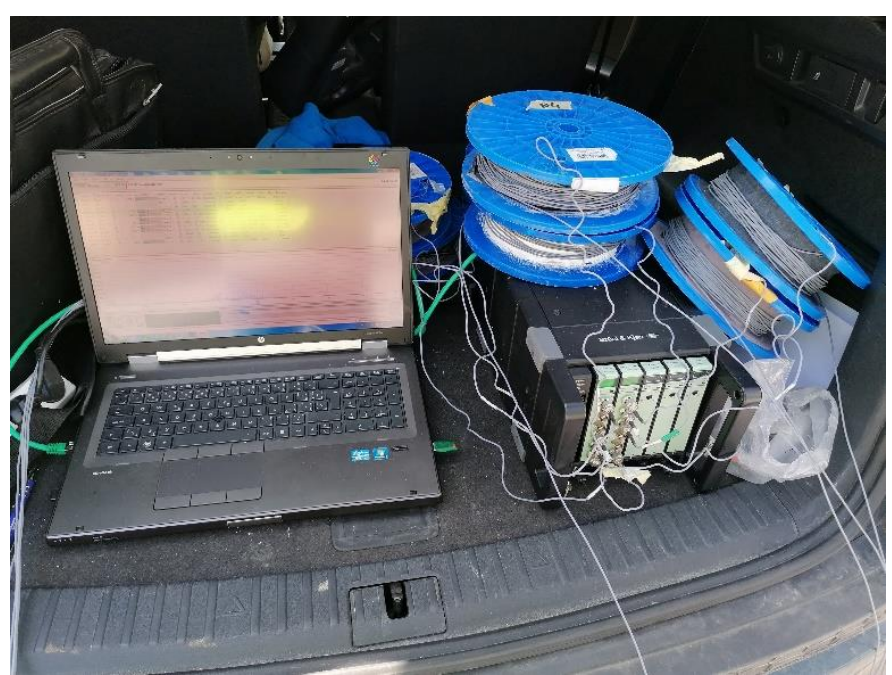

Fig. 5 The measurement and analysis equipment with connections in place

\section{MEASUREMENT PROCEDURE}

Measurement is conducted in several phases. These phases can be defined in terms of five stages, each of which involves different measurement techniques and procedures.

In terms of measurement methodology, the individual stages were carried out using the in-situ off-line method. This method is divided into two parts of on-site data collection and analysis of measured records in the laboratory. The first part always follows the same procedure:

- Analysis of the measured object or measurement task

- Selection of the appropriate experimental technique

- Preparation of instruments, checking and calibration of the sensor network 
- Stabilization of the measured points, mounting of sensors, connection of cables

- On-site inspection and calibration

- Implementation of the measurement itself

- Preliminary check and backup of measurement records

The second part of the experiment is the evaluation of the measured data. Since these are time records of the accelerations of the oscillations at different points and directions, it is also necessary to divide this into the following parts:

- Visual inspection of the time histories

- Amplitude analysis

- Numerical integration

- Spectral analysis

- Outputs, numerical and graphical interpretation of results

The whole measurement phasing followed the main measurement objectives. The results from each stage were used to assess the problem consistently. Each stage was carried out using the same measurement line described in Chapter II. The authors of the paper realized the measurements strived for the most objective results. The objectives of each stage are:

Stage I - identification of the natural frequency range of the ceilings in the affected part of the office building

Stage II - identification of the amplitude and frequency composition of the dynamic load of vibration source 1

Stage III - Identification of the amplitude and frequency response of the dynamic loading of vibration source 2

Stage IV - assessment of the actual condition under standard operation, identification of the dominant source

$\mathrm{V}$. assessment of the proposed vibration isolation solution in terms of vibration attenuation

A. Stage I-Load-bearing structure of the administrative section of the building - vibration receiver, positioning of sensors

The first stage of the measurement aimed to determine the basic dynamic parameters of the investigated building structure. The natural frequencies, of the horizontal loadbearing parts of the structure in the administrative part of the building, were determined by applying a series of impulses in the investigated area and its adjacent rooms. The impulses were induced by a lightweight dynamic plate. (LIGHTWEIGHT DEFLECTOMETER - IMPACTOR). The measurements at this stage required the stopping of two groups of machines believed to be the main source of vibration and all minor sources of vibration located in the administrative part of the building. No persons were to be present on the diagnosed floor during the measurements. At the end of the first stage, a decision was made as to where the sensors would be placed during the subsequent stages of the measurement. Accelerometers were placed according to Fig.6 at the smallest possible distance from the sources and foundations of the building and also at the identified most sensitive point of vibration impact.

\section{B. Stage II - Gradual start-up of source 1}

The aim of stage II was to identify the amplitude and frequency of three-component vibration transmitted from source 1 to the administrative section of the plant. Source 2 had to be inactive during this stage. Fig. 6 is a schematic plan of the positions of the measurement points. During measurement, it was necessary to stabilise points B1, B2, B3 and B4 - which were located next to the base of the machine and outdoors. The points were stabilised using heavy steel targets fixed to the base with plaster (Fig. 7). For measurements within the administrative section, the steel targets were only placed on the floor.

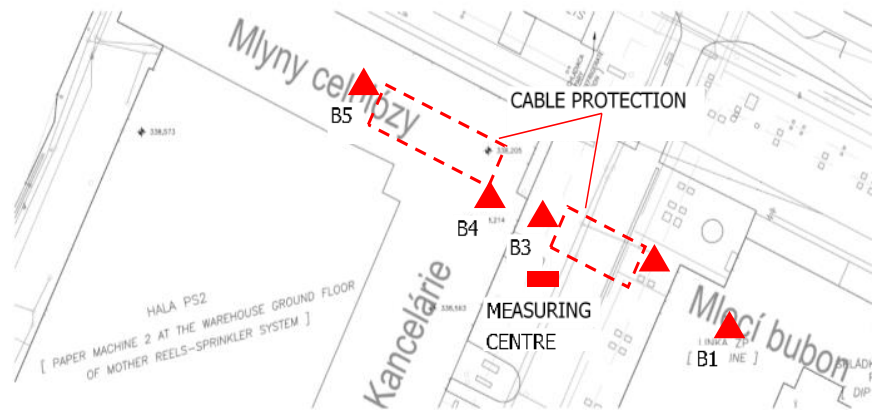

Fig. 6 Schematic plan of the measurement instrument locations during measurement.

\section{Stage III - Gradual start-up of source 2}

The aim of the third stage was to identify the amplitude and frequency of three-component vibration transmitted from source 2 to the administrative section of the plant. Source 1 had to be inactive during this stage. During measurement, it was necessary to stabilise points B4 and B5 (Fig. 6) - which were located next to the base of the machine. The points were stabilised using heavy steel targets fixed to the base with plaster (Fig. 7). For measurements within the administrative section, the steel targets were only placed on the floor.

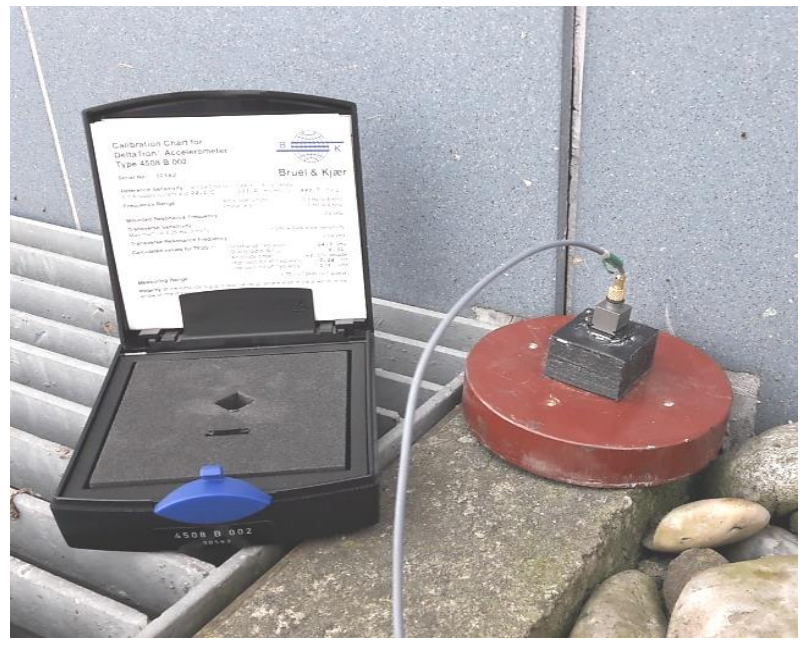

Fig. 7 Accelerometer stabilisation

\section{Stage IV-Normal operation}

In the penultimate stage, the interaction between the two sources and their influence on the resulting vibrations in the 
administrative part of the plant was investigated. At this stage, all measurement points were stabilized (Figure 6). Both sources were operated at maximum power with maximum load (maximum weight of material to be processed). The measured values were compared with the limit values to determine the harmful effect of vibration on people and the structure of the administrative part of the building.

\section{E. Stage V-Measurement of damping}

The last stage could only be carried out after the results of the previous stages had been analysed and the dominant source of undesirable vibrations had been identified. At this stage, experimental measurements were carried out using an isolation layer that could dampen unwanted vibrations from the vibration sources. Damping was measured using two accelerometers oriented in the dominant vertical direction of vibration of the ceiling at point B4. The purpose of measurement was to determine the effectiveness of the most effective possible insulation layer. During dynamic measurement, both sources had to be in operation and employees had to vacate the area where measurement was conducted.

\section{RESULTS OF MEASUREMENTS OF THE DYNAMIC PARAMETERS OF THE ADMINISTRATION SECTION}

To obtain objective dynamic results, measurement of the natural frequencies of the horizontal load-bearing parts of the administrative section was conducted by artificially creating impulses (Stage I). Measurement was conducted during stoppage of the two main vibration sources in the cellulose plant. The purpose was to identify the dynamic characteristics of the location affected by adverse frequencies, which in the present case is the administrative section. Impulses were artificially excited in the structure using an impulse device - a light weight deflectometer - impactor (Fig. 8). This method was used to track the propagation of vibrations through the structure from the impulses produced by the impulse source. The device consists of a steel guide rod down which a weight falls under the influence of gravity and its own weight to strike a circular plate on the surface of the structure. [9]

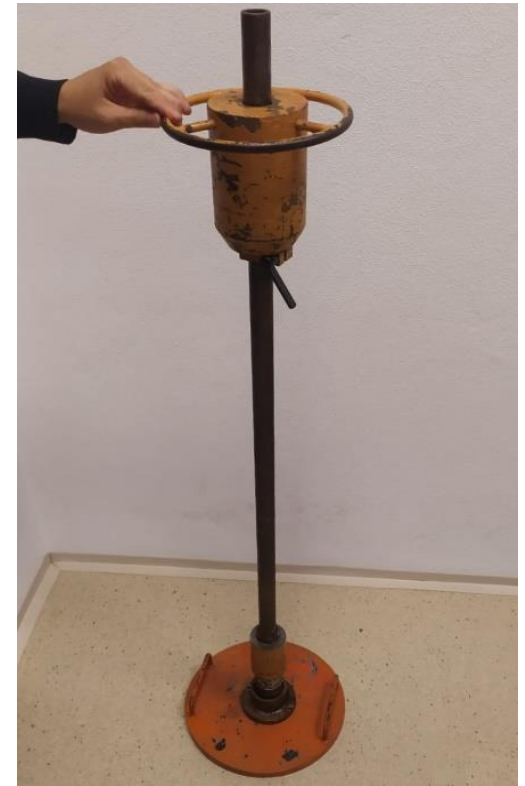

Fig. 8 Light weight deflectometer - impactor

With this method, it is possible to obtain a large number of dynamic parameters of the relevant building and the related frequency spectrum. The resulting averaged spectrum is shown in Fig. 9. It is produced by evaluating the correlated frequency transfer functions from the impulse source to the place of measurement. The most important natural frequencies were in the range from $\mathbf{1 2 H z}$ to $21 \mathrm{~Hz}$. Frequencies from $50 \mathrm{~Hz}$ to $55 \mathrm{~Hz}$ were also sensitive. The value of the first natural frequency was $f_{l}=13.7 \mathrm{~Hz}$.

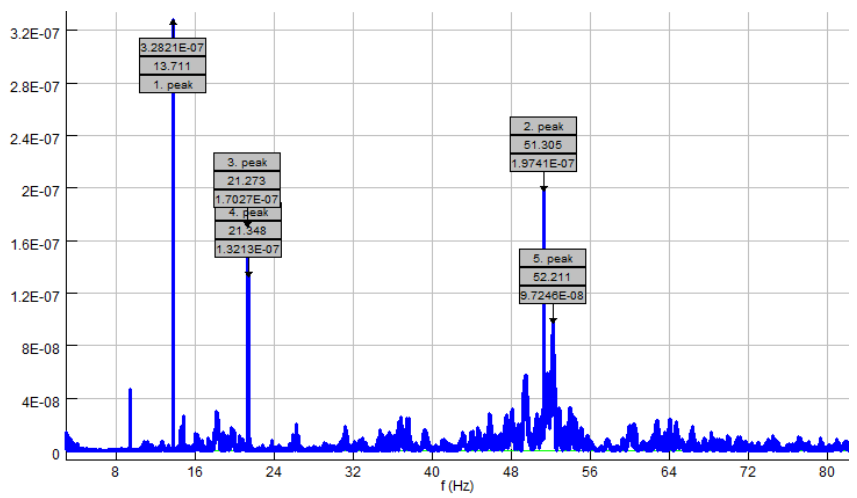

Fig. 9 Resulting frequency spectrum - correlated transmission

\section{RESULTS OF MEASUREMENT DURING NORMAL OPERATION WITH BOTH SOURCES AT FULL POWER}

A series of measurements were taken during full operation with the sources at full power. This was the next stage in the experimental measurements. The purpose was to identify safe levels of vibration for people and for the building structure. The following graphs summarise the results for maximum vibration acceleration and velocity. 


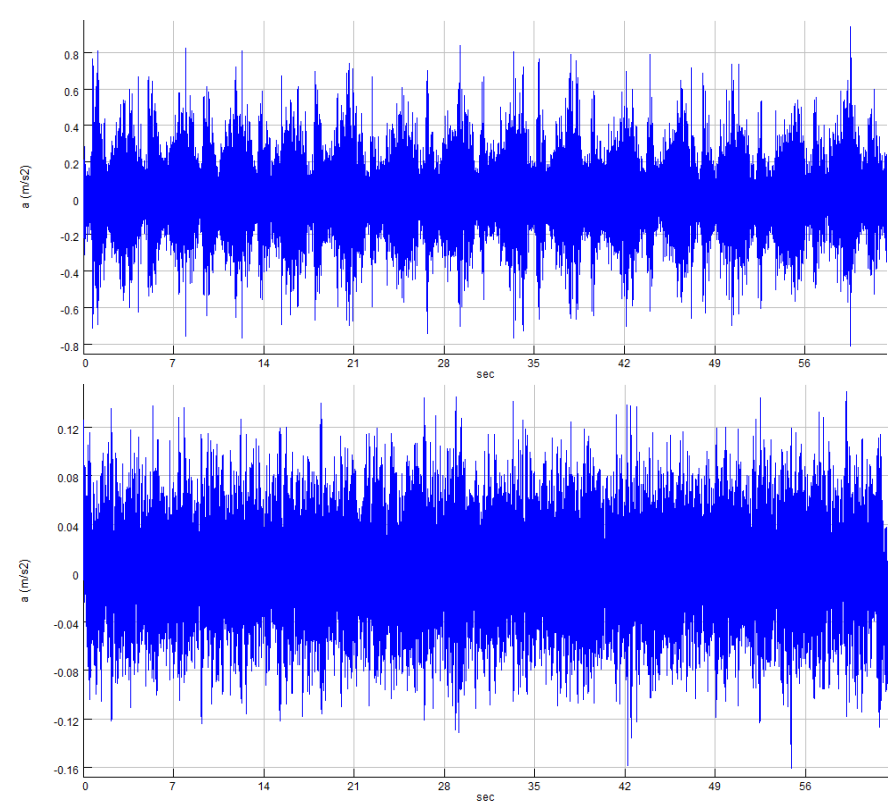

Fig. 10 Maximum acceleration - vibration sources

Fig. 10 shows the behaviour of the spatial acceleration vector for the measured points immediately adjacent to the sources. This area produced the highest values for all measurements. During monitoring of the effects of the individual sources, the response at point B4 was evaluated with reference to STN EN 730036 (building limit states) [10] and Decree No 549/2007 (hygienic regulation relating to vibration effects on the human body) [11].

Fig. 11 shows the spatial vector (X, Y and $\mathrm{Z}$ components) of vibration acceleration and velocity for point B4. Figs. 13 to 16 show the stages of a one-third octave bank analysis of ceiling vibration in areas where people can be affected. The result is an equivalent weighted acceleration value of $a_{w, e q}=0.0054 \mathrm{~ms}^{-2}$. The limit value under the decree of the Ministry of Health is $0.008 \mathrm{~ms}^{-2}$.

The maximum permissible values for the critical quantities of vibration in the working environment laid down in the Regulation apply to vibration occurring on the surface of structures and objects at points from which it can be transmitted to man. According to the type of transmission, maximum permissible values are laid down for vibration transmitted to the hands, maximum permissible values for vibration transmitted to the whole body and maximum permissible values for local vibration. The maximum permissible values for the vibration determinants also apply to vibrations where the major part of their energy is contained in third-octave bands with a mean frequency of between $1 \mathrm{~Hz}$ and $80 \mathrm{~Hz}$. For the purpose of the study, the governing quantity was the equivalent weighted acceleration. The equivalent acceleration for the realization of a random process is defined as an integral quantity which can be determined either from the time record of acceleration or from the amplitude spectrum. Based on Parseval's theorem, weighting coefficients can be applied to the individual frequency bands to obtain the equivalent weighted acceleration [10].

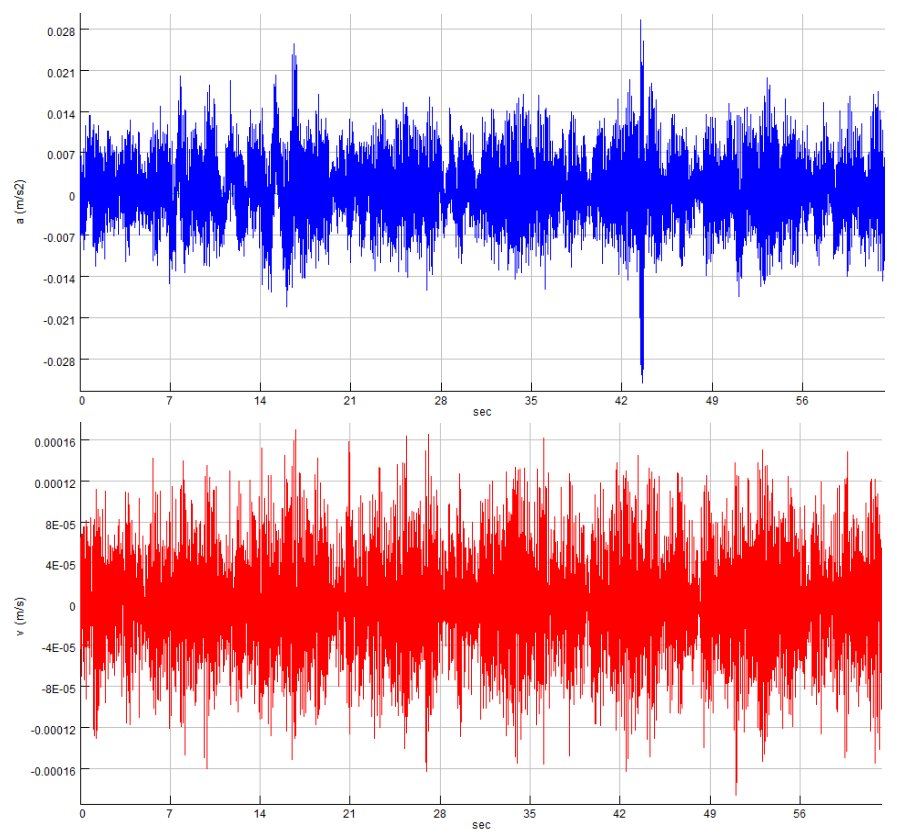

Fig. 11 Maximum vibration acceleration and velocity - area of interest (ceiling of the administration section)

Likewise, the highest measured value for vibration velocity $-v_{R M S}=0.05 \mathrm{~mm} \cdot \mathrm{s}^{-1}-$ was far below the standard limit of 2 $\mathrm{mm} \cdot \mathrm{s}^{-1}$.

The following graphs (Figs. 12 to 15 ) further illustrate the interpretation of the measured parameters. They show a onethird octave band analysis of vibration velocity, vibration acceleration values in groups, the group weighting factors and equivalent weighted acceleration of vibration.

The response under technical seismic shaking loads is generally assessed by the value of the effective vibration velocity at the lowest floor or on the foundations of the building. These locations are called reference positions. objects subjected to technical seismicity are evaluated based on the limit value

effective vibration velocity, the values of which correspond to the specified 6 classes of resistance of the object and 4 classes of significance of the object. The building assessed in the presented study falls into resistance class 2 and significance class 3. [11]

Interpretation of oscillation acceleration in the third octave band

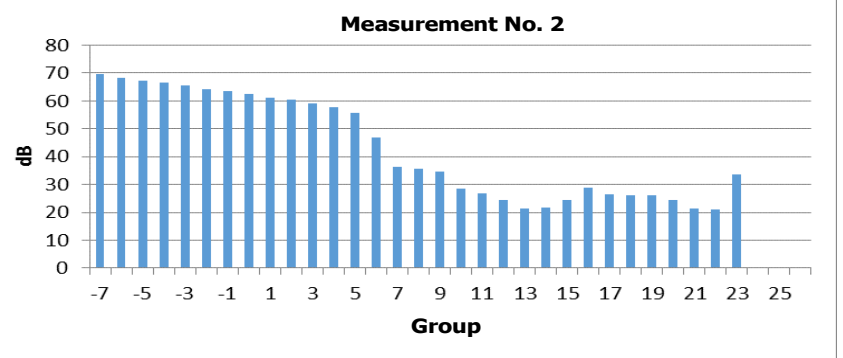

Fig. 12 One-third octave band analysis of vibration acceleration 

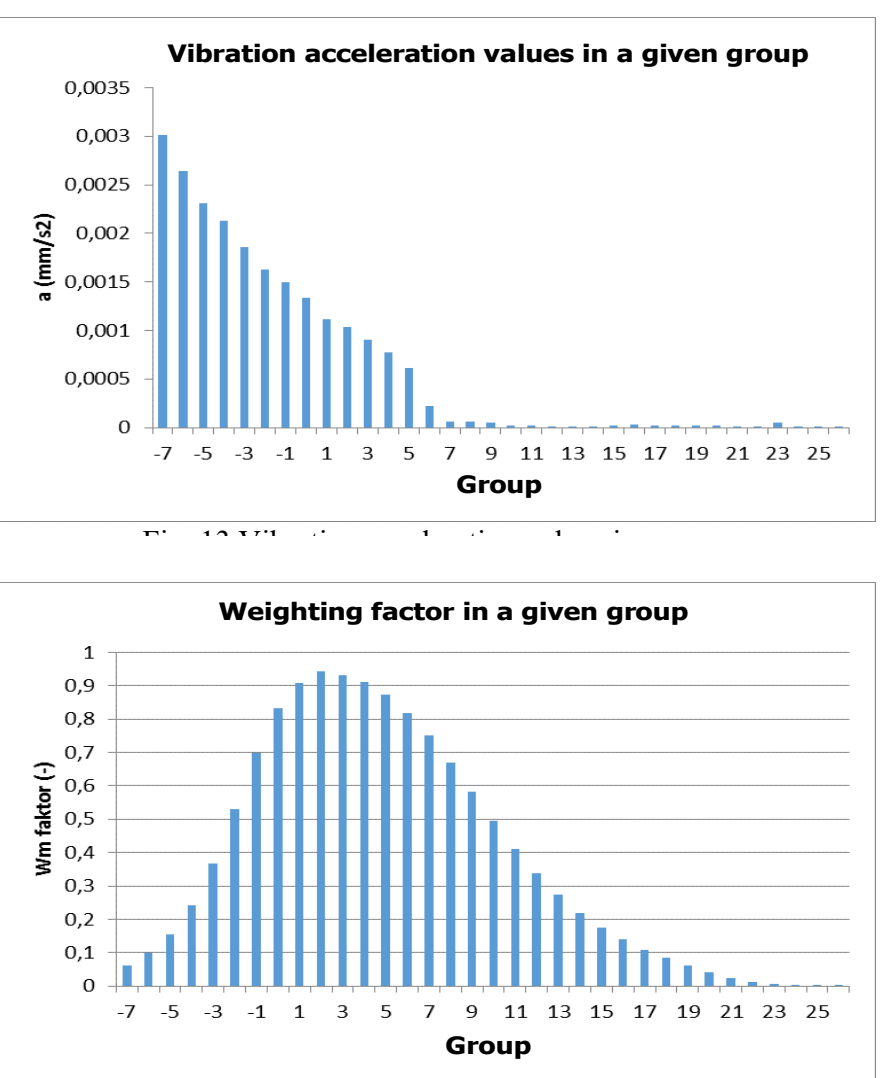

Fig. 14 Group weighting factor

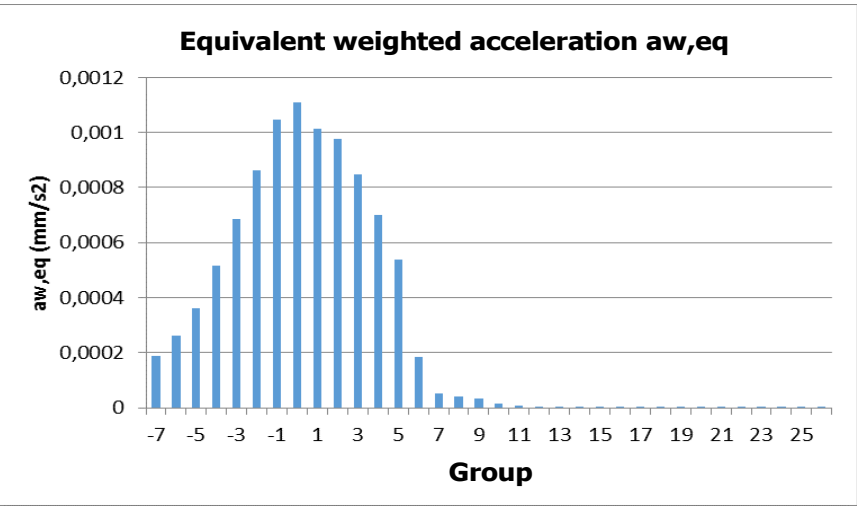

Fig. 15 Equivalent weighted acceleration of vibration

VI. RESULTS OF MEASUREMENT OF VIBRATION TRANSMITTED FROM THE TWO SOURCES - START-UP TO NORMAL OPERATIONS

This section summarises the results of Stage IV in the sequence defined in Section III. Measurements for the start-up of sources 1 and 2 from the quiescent (inactive) state to the full operation were performed separately. The reasons for this post were:

- to pass through all frequency bands up to the operating frequency of each source

- the sweep allows the identification of frequencies close to the natural frequencies of the building

- each of the sources has an individual distance, geological environment and working frequency

- to facilitate the identification of the cause of excessive vibration experienced in the office area due to ceiling vibration.

The start-up of source 1 took longer and therefore measurement had to be divided into two parts.

Figs. 16 and 17 show the outputs that characterise the effects of each source presented in the form of a correlated amplitude and frequency spectrum.

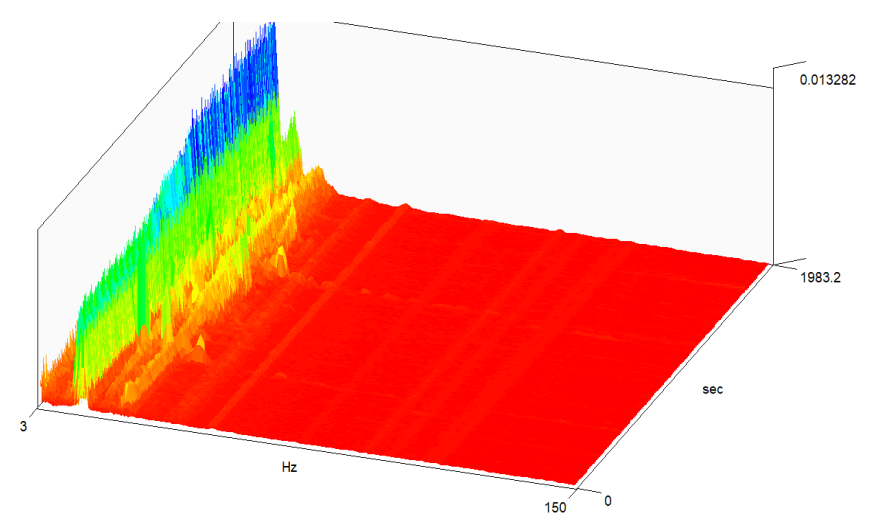

Fig. 16 Development of amplitude and frequency characteristics over time for source 1

During measurement, various combinations of mats and two types of foam concrete were used.

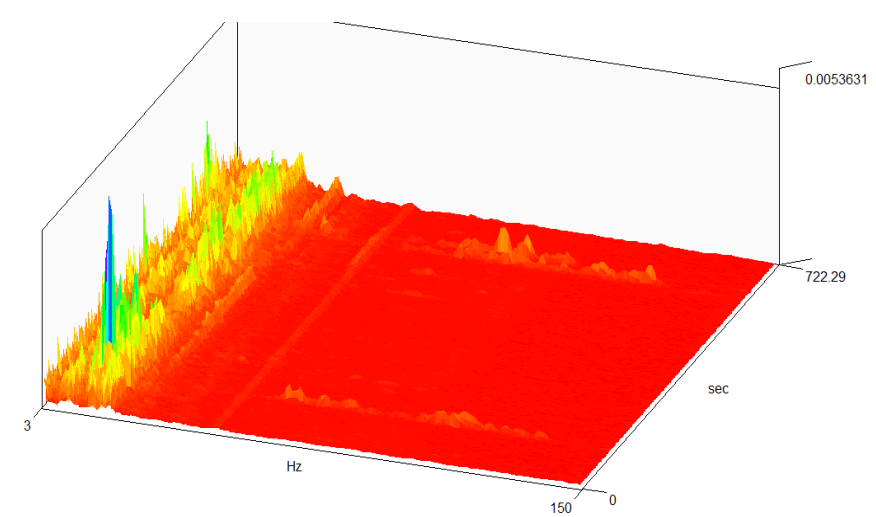

Fig. 17 Development of amplitude and frequency characteristics over time for source 2

\section{RESULTS OF MEASUREMENT OF THE DAMPING PROVIDED BY INSULATION LAYERS}

When it was confirmed that the vibrations were transmitted from source 1, the damping provided by one of the most effective insulation layers was tested on site. This layer is made up of an insulating mat of variable density polyurethane and FC 250 foam concrete. It is the most effective form of insulation against sound and vibration, but its effectiveness is greater at relatively high frequencies.

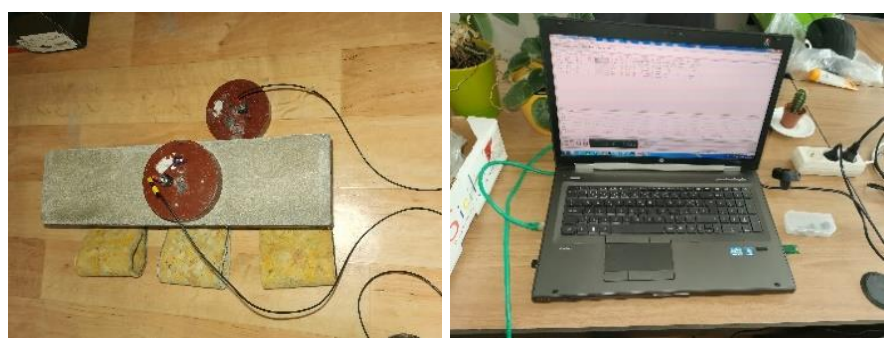


Fig. 18 Measuring the effect of an insulation layer.

The photographs in Fig. 18 illustrate the measurement procedure. A sample of FC 250 is mounted on a $3 \times 0.5 \mathrm{~cm}$ mat of variable density polyurethane. Fig. 19 shows the results in the form of the amplitude spectrum for vertical vibrations on the floor (without damping). Fig. 20 shows the decrease in amplitude on the upper surface of the insulation layer - the amplitude spectrum for vertical vibration acceleration on the most effective insulation layer. [12, 13].

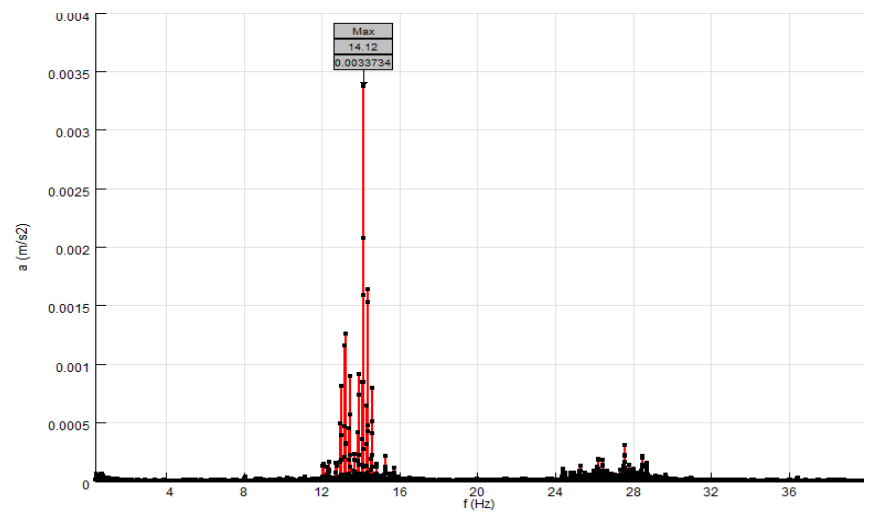

Fig. 19 Amplitude spectrum of vertical vibration acceleration - on the floor without damping

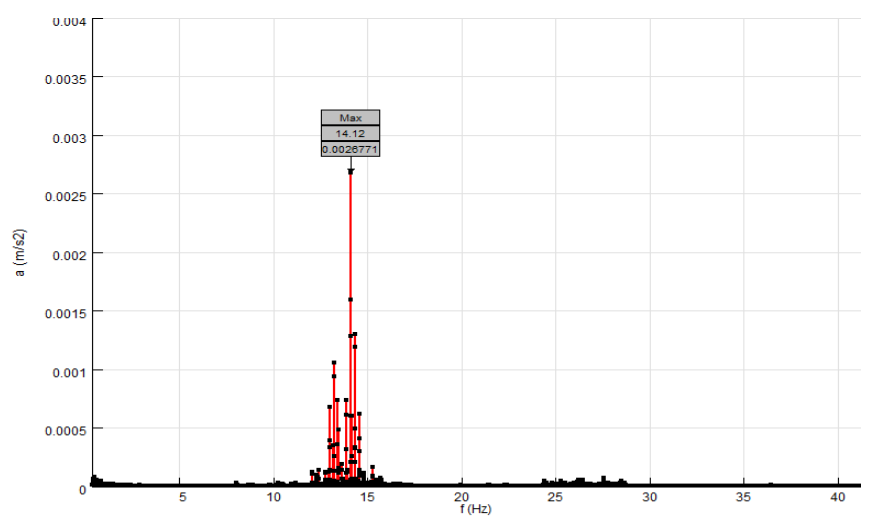

Fig. 20 Amplitude spectrum of vertical vibration acceleration - on the most effective insulation layer - measurement 14

\section{CONCLUSIONS AND RECOMMENDATIONS}

The article's conclusions can be divided into two categories - those relating to the case study itself and general conclusions for research and education.

The conclusions of the case study were as follows:

- Stage I identified the most important natural frequency band for the ceiling support structures as 12-15 Hz.

- Stage II and Stage III identified the dissolving drum (source 1) as the dominant source of vibration.

- Activation of source 1 generates vibrations that are propagated through the geological environment to the administrative section at frequencies close to the natural frequency of the horizontal load-bearing parts of the structure independently of the drum's power and load.

- Analysis of the measurements in Stage IV found that the vibrations do not exceed the limit values laid down in standards or hygiene regulations and are therefore not harmful to the building structure or people within it.

- The experimental measurements with passive insulation in Stage $\mathrm{V}$ found that the tested insulation material had a low absorption potential. Use of a layer of foam concrete and a polyurethane mat does not reduce the amplitude below $80 \%$ of the undamped level, which is insufficient.

- Increasing the frequency by reinforcing the ceiling from below would have little effect because of the construction system used for the ceiling. It would be more cost-effective to move administration to another workplace.

The general conclusions can be summarised under the following points:

- The measurement of dynamic parameters is of clear benefit to the teaching process, especially if it conducted as part of an experiment in the field.

- Measurement equipment, measurement systems and evaluation software and accessories should be chosen having regard for the aim of measurement. Low-sensitivity instruments with a broad spectrum cannot be used for measurements when expecting a low-amplitude response at low frequencies.

- The evaluation of measured data is also a multi-phase process from the disaggregation of relevant items through purpose-oriented records to the interpretation of results. In the education process, it is possible to separate the processing of results from measurement. In this case, it is possible to speak of an "offline" method.

- The evaluation of individual case studies must be carried out in accordance with applicable standards and legislation laying down requirements for measurement procedures, especially as regards the limit values for individual parameters.

Technical seismicity caused by machinery can be used as an example of the evaluation of an extraordinary dynamic load for both original scientific research and the incorporation of practical research activities into the education process. It means that all original findings in dynamic measurements of a similar character extend the knowledge base of the real behaviour of building structures. Measurements are also a tool for verification and updating of numerical models and simulations often carried out in research or education. Specific case studies allow the demonstration of all the skills necessary for carrying out a dynamic experiment in practice $[14,15,16]$.

The discussion of the research contribution of the article can be divided into the following points:

1. Interpretations: the results of measurements and expert analyses represent the dynamic response of the whole system from the vibration source to the building and the human body. It is a case study of the problem of the effects of adverse vibration arising from the manufacturing process. 
2. Implications: The negative effects of vibration are divided into two impact groups that is the building structure and the human body. Each of these groups has to be considered according to individual criteria. The findings of this study also include the effect of technical seismicity through which the vibration propagates from the source. This raises the question to what extent does the geological composition influence the transmission of vibrations? This question can only be answered by numerous studies of a similar type.

3. Limitations: The results cannot describe in detail the propagation of vibrations on the whole distance from the source. This is due to the limited number of measured points due to the limited number of acceleration sensors.

4. Recommendations: Currently, two types of vibration isolation are used: active (damping at the source) and passive (protection of the building or floor under people). Some works also describe the use of vibration isolation trenches placed between the source and the affected building. A possible challenge for further research is to find a suitable and cost-effective combination of these systems.

The contribution of the approach presented in the experimental study is mainly in the reasonable division of the measurements into different phases with their detailed analysis. Compared to the studies reported in the references $[17,18,19]$, it is possible to apply a wider potential of analytical evaluation tools and to assess effects more accurately in terms of standards and regulations. The advantages of the study presented in the paper are mainly its comprehensiveness and the integration of several scientific fields such as civil engineering, mechanical engineering, seismic engineering, application of medical criteria, etc. The interdisciplinarity of such studies is significant and facilitates both research and education.

\section{ACKNOWLEDGMENT}

Authors kindly acknowledge supporting organisation Metsä Tissue Corporation, for access to publishing measured data from special dynamic analysis for administrative building effects due to production processes. Also, the acknowledgment belongs to University of Zilina, Faculty of Civil Engineering, Department of structural mechanics and applied mathematics and department laboratory for measurement equipment ability to using for experimental works.

\section{References}

[1] Lahdelma S, Juuso E. Generalised lp norms in vibration analysis of process equipments. Proceedings CM. 2010 Jun 22:614-26.

[2] Björk A, Danielsson LG. Predicting pulp quality from process acoustic measurements on a medium concistency pulp stream. JPAC, Journal of Process Analytical Chemistry. 2006;10(1):1-5.
[3] Ainalis D, Ducarne L, Kaufmann O, Tshibangu JP, Verlinden O, Kouroussis G. Improved analysis of ground vibrations produced by man-made sources. Science of the Total Environment. 2018 Mar 1;616:517-30.

[4] J. Fridrich. "Design of building Chemocelulozá n.p. Zilina”, Cheppik Bratislava, 1979

[5] J. Pyri, "Machinery design - Fiberflow FF200", AHLSTORM Machinery, Krahula, 1992

[6] Brüel\&Kjær PU. Version 8.0. Sound \& Vibration Measu. 1996;2003.

[7] García-Barruetabeña J, Martínez FC. Dynamic Transient Response of Viscoelastic Structures. Viscoelastic and Viscoplastic Materials. 2016 Sep 21:245.

[8] Papan D, Papanova Z, Krkoskova K. Experimental dynamic analysis of traffic seismicity effect on historical building. InE3S Web of Conferences 2019 (Vol. 106, p. 01018). EDP Sciences.

[9] Li K, Darby AP. An experimental investigation into the use of a buffered impact damper. Journal of sound and vibration. 2006 Apr 4;291(3-5):844-60.

[10] STN 730036 - Seismic load on structures, 1997, (in Slovak)

[11] Decree of the Ministry of Health No. 549/2007 Coll. on Permissible Levels of Noise, Infrasound and Vibration and on the Objectification Requirements for Noise, Infrasound and Vibration in the Environment (Slovak Republic) (in Slovak)

[12] Papán D, Papánová Z. Higher frequency dynamic response analysis of the foam concrete block element. InMATEC Web of conferences 2018 (Vol. 196, p. 01037). EDP Sciences.

[13] Huang JJ, Su Q, Zhao WH, Li T, Zhang XX. Experimental study on use of lightweight foam concrete as subgrade bed filler of ballastless track. Construction and Building Materials. 2017 Sep 15;149:911-20.

[14] Sivasuriyan A, Vijayan DS, Górski W, Wodzyński Ł, Vaverková MD, Koda E. Practical implementation of structural health monitoring in multi-story buildings. Buildings. 2021 Jun;11(6):263.

[15] Goyal D, Pabla BS. The vibration monitoring methods and signal processing techniques for structural health monitoring: a review. Archives of Computational Methods in Engineering. 2016 Dec;23(4):585-94.

[16] DeVore C, Ahlberg E. Review of the Codes and Standards for Noise and Vibration Investigations in Buildings. InForensic Engineering 20152015 (pp. 860867).

[17] Papán D, Demeterová K, Valašková V, Kampf R, Ližbetin J. The Dynamic Analysis of the Green Anode Processing Building. Procedia Engineering. 2016 Jan $1 ;(161: 47-53)$.

[18] Benčat J, Papán D, Stehlíková M. Dynamic Response of Buildings and Structures due to Microtremor Part 1: Industrial Machines Effects. InAdvanced Materials Research 2014 (Vol. 969, pp. 125-132). Trans Tech Publications Ltd.

[19]Benčat J. Industrial machinery dynamic effects on production process and hall structures. ENGINEERING MECHANICS 2014, Svratka, Czech Republic, 12 - 15 May 2014 
Contribution of Individual Authors to the Creation of a Scientific Article (Ghostwriting Policy)

Daniel Papán carried out the experimental measurements and several evaluations and analyses.

Zuzana Pápanová realised dominant number of analyses and evaluations of recorded data from experimental measurements. Bibiana Martinovičová processed an interpretation of evaluated results and export numerical and graphical outputs.

\section{Creative Commons Attribution License $\mathbf{4 . 0}$}

(Attribution 4.0 International, CC BY 4.0)

This article is published under the terms of the Creative Commons Attribution License 4.0

https://creativecommons.org/licenses/by/4.0/deed.en_US 